Postgrad. Med. J. (1966), 42, 623.

\title{
THE EPIDEMIOLOGY AND CLINICAL FEATURES OF ASBESTOSIS AND RELATED DISEASES
}

\author{
P. C. Elmes, B.M., M.D., M.R.C.P. \\ Reader in Therapeutics and Pharmacology, \\ Institute of Clinical Science, The Queen's University of Belfast, Belfast 12.
}

DURING the last 100 years many materials have been used by industry for a while and then found to have unexpected harmful effects. Usually the risk ceases when safety measures are adopted but sometimes these measures are found to be inadequate and new ones must be introduced. This has happened recently after the re-investigation of flax byssinosis (Carey, Elwood, McAulay, Merrett and Pemberton, 1965).

But with asbestos the situation is not so simple. Following the report in 1930 (Merewether and Price) on the dangers of exposure to asbestos dust safety measures were adopted in factories and certain workers kept under medical surveillance. Since then a series of other risks have been recognised which indicate that the measures were either inadequate or did not cover a sufficiently wide variety of asbestos workers. Both cancer of the lung and mesothelioma are now recognised as resulting from levels of exposure to asbestos which still occur in spite of these measures.

The summary of present knowledge about the epidemiology of asbestosis and related diseases which follows is necessarily brief and emphasises those points at which our knowledge is as yet incomplete.

\section{The Nature and Uses of Asbestos}

The word asbestos is used to cover a group of fibrous silicate minerals whose chief value is that they have a high melting point and are non-inflammable. Therefore asbestos is used as strengthening or insulation where high temperatures occur. But because it is relatively cheap and strong (the fibres are comparable in tensile strength to steel), and is resistant to many chemicals and to abrasion, asbestos has many other uses. These other uses account for the increased consumption of asbestos in an industrial city since 1940 (Fig. 1) (Elmes and Wade, 1965). Asbestos cement is used to protect the steel framework of modern buildings against fire, to form pipes and ducts for water, air and chemicals and to form corrugated roofing. Asbestos is incorporated in brake pads and linings and in heavy duty flooring. Soft asbestos boarding and tiles are used to give heat and sound insulation to ceilings and asbestos is sprayed on to the insides of air conditioning ducts, roofs and pipes to prevent condensation. Asbestos is spun and woven to make fire protective clothing, oven cloths, wicks for oi⿺ stoves etc. It is even used in the filters of certaito types of gas mask.

Three types, chrysotile, crocidolite and amosite make up the bulk of the asbestos used. Of the others such as tremolite and actinolite only anthophyllite is of particular medical interest. Chrysotile is mined in the greatest quantity and is mineralogically separate from the others being a pyroxene while the others are amphiboles (Table 1). They were all formed early in geological history probably about 2,000 million years ago. They were produced when the original rocks were subjected to hot water under pressure. As the rock formation cooled these compound silicates crystallised out in fibrous form. The type of deposit and length of fibres depended on the condition of the parent rock. Most chrysotile asbestos was formed in cracks between shattered fragments of serpentine, a relatively hard rock. But the amphibole asbestoses were deposited in the interstices of sedimentary rocks such as banded ironstones. Harrington (1962) has demonstrated the presence of oils and waxes which suggest that organic matter must have been present when the fibres formed. These may be the cause of the fibrogenic and carcinogenic activity of asbestos.

\section{Modes of Exposure}

Mining

Asbestos is obtained from both open cast and 
SHIPBUILDING and ASBESTOS IMPORTS.

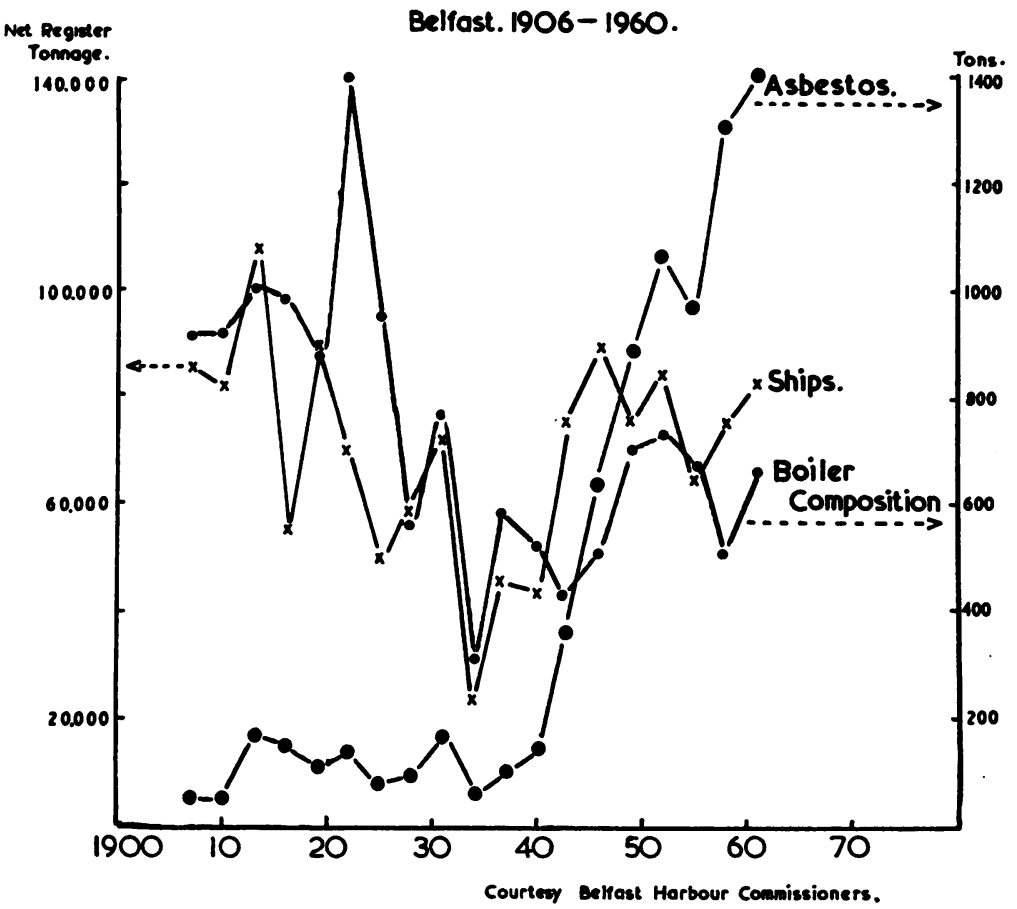

FIG. 1-The dramatic increase in tonnage of asbestos imported to Belfast since 1940. (See Elmes \& Wade, 1965).

TABLE 1

Kinds of Asbestos in Commercial Use

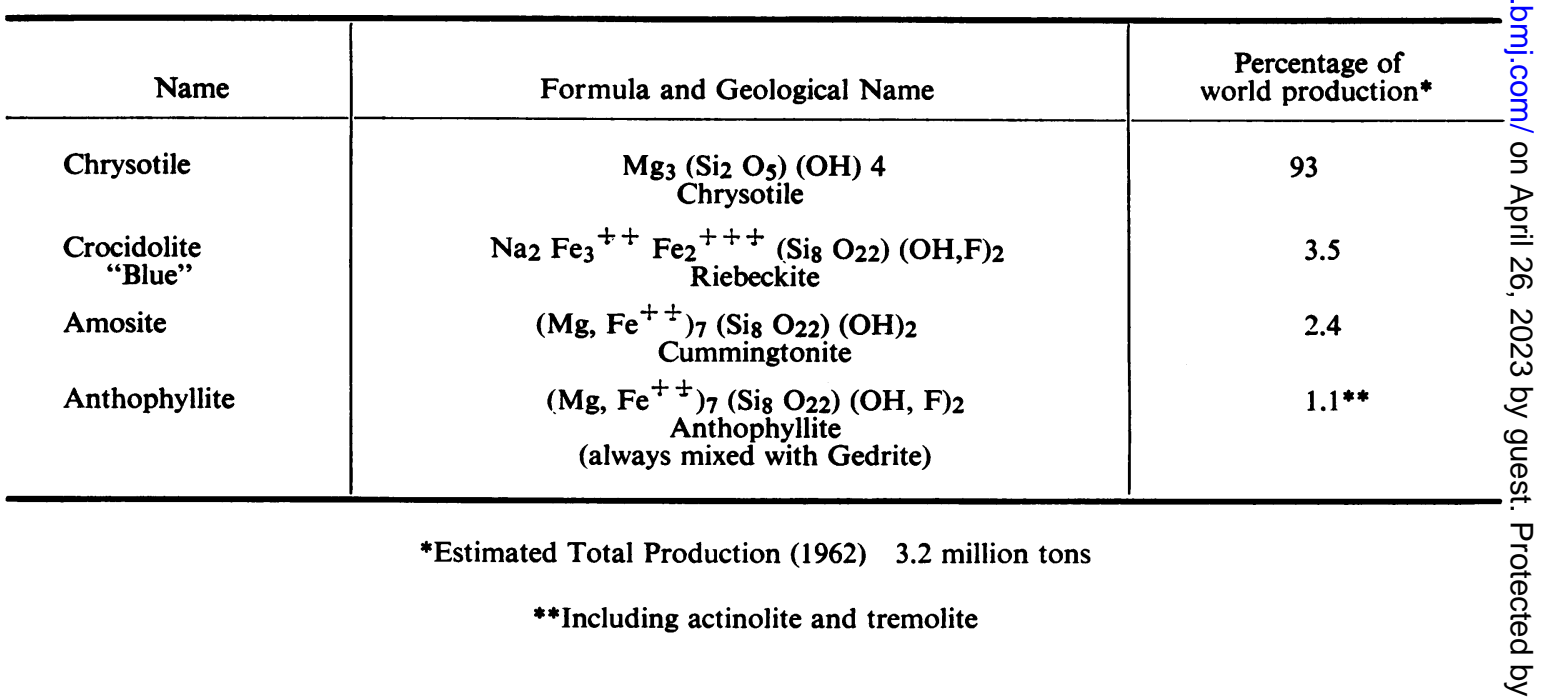


deep mines. Drilling and explosives are used when the host rock is hard and mechanical excavation when it is softer. The crude ore is milled to remove the host rock and the fibrous asbestos is partially teazed out before it is packed into bags. Where labour is cheap some of the separation of rock from fibre is done by hand (cobbing) by women often accompanied by their babies. Until recently large amounts of asbestos fibre escaped into the air from the mines and mills so that not only the miners and millers but the whole population of the mining towns and the surrounding countryside have been exposed.

It was customary to transport asbestos from the mines to the factories in jute bags. This exposure of a whole series of transport workers could be eliminated by using sealed impervious bags.

\section{Work in asbestos factories}

It was here that the danger of exposure to asbestos dust was first recognised and investigated. The asbestos is teazed out again so that the fibres are separated and particles of rock etc., removed. The next process depends upon whether the fibre is to be woven into a textile or mixed with some binding material for the fabrication of boards, pipes etc. The textile procedures are similar to those used in the wool and cotton industries, carding being the dustiest. In the fabrication of board and cement products there was a considerable hazard when the product was cut and trimmed or machined.

No special effort was made to suppress dust in these factories and the dust was everywhere in them. Although all workers, even the clerks in the offices, were exposed, some jobs were worse than others. Where forced ventilation was used the dusty air was often discharged unfiltered producing high levels of air pollution close to the factories.

The protection of workers at certain scheduled processes from asbestos dust became compulsory under the Government regulations which followed the publication of the Merewether report (Merewether and Price, 1930). The workers also came under compulsory medical supervision and there was an incentive for the relatives to ask for an autopsy when a death occurred. Cleaning up the very dusty processes and filtering the effluent of the exhaust ventilation systems also reduced the general air pollution of the factory and its environment.

Although measurements of the dust concentrations were started at this time they are technically difficult. They may not detect the smallest fibres, and these may be as harmful and be disseminated more widely than the larger fibres.

\section{Use of asbestos goods}

The products of the asbestos factories are not usually supplied direct to the public but are used in the manufacture of factories, houses, power units, ships, cars, domestic stoves etc., by a variety of skilled tradesmen with their helpers. These men sometimes use powdered material which they mix and apply on the spot or they use prefabricated blocks, quilts etc., which require cutting, sawing or shaping to make them fit. The materials are usually rough-finished when they leave the factory and release some dust when handled by storemen and transport workers. Insulation workers have been using asbestos goods in this way for a long time. More recently building workers, interior decorators and many others have started to use them. Others (electricians, plumbers, fitters, painters etc.) may work in the same confined space as insulators and become exposed to the same dust or may create dust cutting or drilling asbestos material in the course of their own work.

Most asbestos materials are coated with paint or sandwiched between other materials so that they do not present a continuing risk until the building or installation is demolished. But asbestos roofing and brake linings must cause some general atmospheric pollution and certain uses such as the lining of air condition ducts with soft asbestos and the use of unsealed ceiling tiles cause continuous pollution of the air of office and factory buildings where people work all day.

A simple industrial history will not necessarily reveal exposure to asbestos when this has occurred. A careful description of the type of work and the materials encountered at work will often help but there remains the unpredictable exposures which will only be revealed by chance. A woman of 53 (Fig. 2) was recently investigated following a spontaneous pneumothorax. She had been increasingly breathless and been under observation by the Chest Clinic because of pulmonary fibrosis for several years. The findings were compatible with asbestosis but the patient denied occupational exposure. A few days later she told the house physician that she had helped her husband build two asbestos bungalows in $1947-8$. She had held the sheets while her husband sawed them up and they lived in one of the bungalows for about two years before painting over the asbestos sheets lining the walls and ceilings. The husband was a deck-hand on a long-haul merchantman and also had no 'occupational' exposure to asbestos. X-rays taken when he was next in port revealed a similar extensive fibrosis although he was still able to work. Similar unexpected sources of exposure can be revealed by retrospective investigation of patients dying of asbestosis or its complications. Newhouse and Thompson (1965) describe the wife who brushed the asbestos dust off her husband's clothes when he came home in the evenings. 


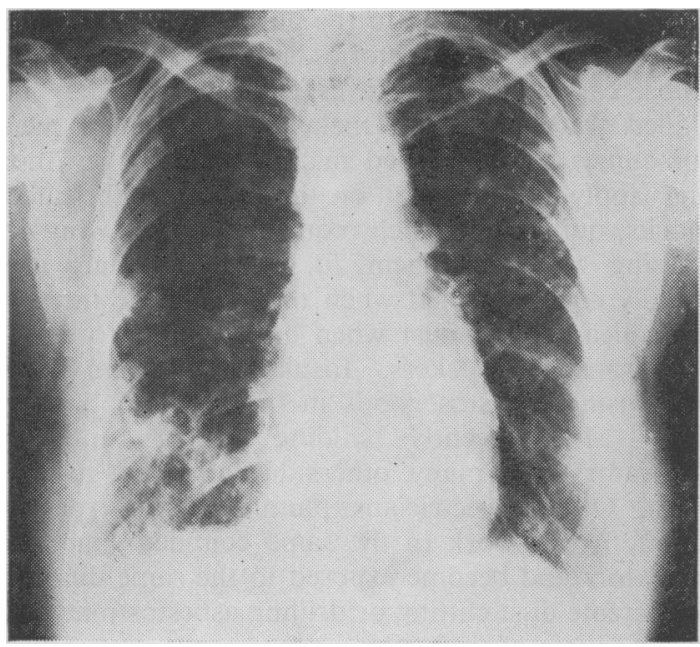

Fig. 2-Woman aged 53 who helped her husband build two asbestos bungalows 18 years before. Her husband shows similar changes. Diffuse fibrosis with linear markings in the lower zones. Pleural thickening with loss of clear demarcation of diaphragms. The scarring or 'large opacities' in the middle and upper zones may represent inactive tuberculosis.

\section{The Diseases Related to Asbestos Exposure \\ Asbestosis}

Many descriptions of asbestosis appeared in the literature between 1924 and 1933. Descriptions such as those of Seiler (1928), Cooke (1927), Oliver (1927) and Wood (1928) refer to fibrosis resulting from a level of dust exposure far in excess of those experienced now. There have been two changes since, the disease now comes on more slowly and there has been a virtual disappearance of concomitant tuberculosis. In Wyers' series (Wyers', 1949) collected at an east London factory between
1931 and 1949 no less than $31 \%$ had active tuber- 3 culosis at necropsy compared with only 4 healed $\stackrel{\triangleright}{\complement}$ lesions found in 71 necropsies carried out between $ᄃ$ 1957 and 1964 on cases from the same source $\overrightarrow{\bar{F}}$ (Table 2) (Smither, 1965).

This difference in exposure and absence of complicating tuberculosis results in a more insidious $\overline{\bar{c}}$ onset of symptoms which may start 20 or 30 years $\vec{\mathbb{}}$ after first exposure to asbestos and may even $\bigcirc$ develop years after the exposure has ceased.

\section{Symptoms}

The first symptoms are breathlessness on exertion $\vec{\omega}$ and productive cough. The breathlessness is 0 relatively severe compared with the accompanying 3 cough and spit and is not associated with upper respiratory infections or adverse weather conditions. But when 50 asbestos workers were carefully co matched with controls recently both severe cough o and more than minimal sputum production were significantly more frequent.

Pain in the chest is emphasised in the earlyliterature, but our patients more often complain of $O$ a 'tightness' than a pain. This is unrelated to effort $\frac{?}{0}$ and comes and goes unpredictably. Sometimes it may be described as a pain by the younger and more apprehensive asbestos worker who may show definite evidence of asbestosis. Severe gnawing. pain suggests the development of some complicatiot.

Clubbing and warts: As in other conditions of insidious onset associated with clubbing of the fingers only the occasional patient is aware of it. Clubbing does not seem to occur in the absence of $\frac{\mathcal{Q}}{\mathscr{Q}}$ significant chest disese and is not invariably present $\vec{F}$ when the chest disease is severe. Warts are common $\frac{3}{3}$ in people who handle asbestos and are liable to have cuts or abrasions of their hands. 42 per cent of a group of 100 insulators had these at the time of examination and a further 26 had had them in the 3 .

TABLE 2

Post Mortem Findings in Asbestos Factory Workers

(AfTER SMITHER 1965)

\begin{tabular}{|c|c|c|}
\hline & $1931-49$ & $1957-64$ \\
\hline $\begin{array}{l}\text { Number of cases } \\
\text { Age at death } \\
\text { Tuberculosis } \\
\text { Carcinoma of lung } \\
\text { Primary pleural malignancy } \\
\text { Primary peritoneal malignancy } \\
\text { Other abdominal malignancy }\end{array}$ & $\begin{array}{l}115 \\
40.8 \\
36 \\
17 \\
1 \\
0 \\
7\end{array}$ & $\begin{array}{l}71 \\
56 \\
4^{*} \\
26 \\
2 \\
13 \\
7\end{array}$ \\
\hline
\end{tabular}




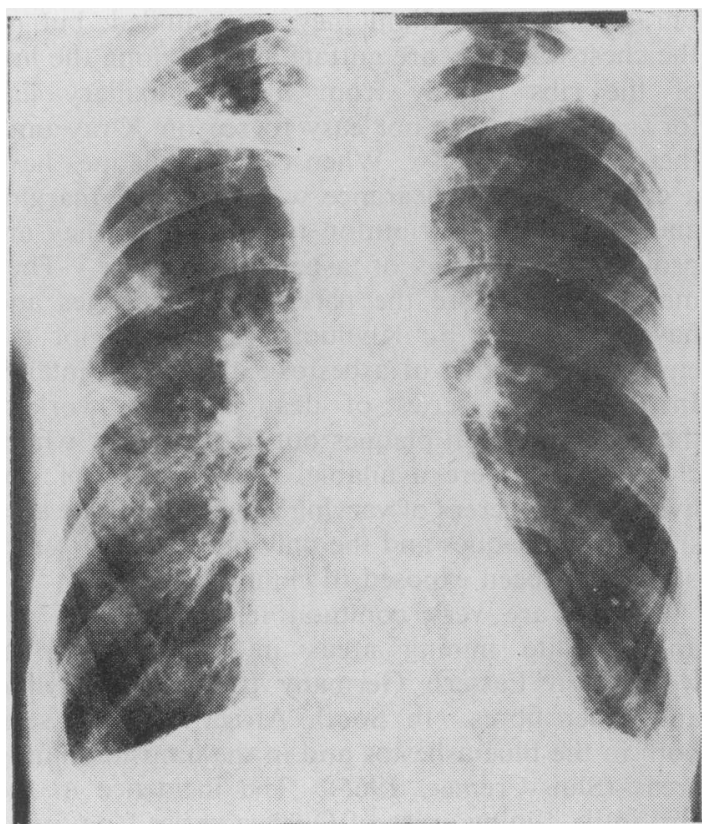

FIG. 3-Pipe coverer (insulation worker) for 16 years; died at 65 years of carcinoma of the stomach. No metastasis found in the lung at postmortem. Diffuse fibrosis with linear markings in the middle and lower lobes. Loss of clear outline of both diaphragms. The scarring in the right upper zone was not tuberculous.

past. They start as a lump in the skin which becomes hyperkeratotic and a central white area appears. If this centre is picked out with a pin the lesion will disappear but otherwise it will persist for months or years.

\section{Physical signs}

The main features of the more severe case are cyanosis, restricted chest movement, kyphosis, fine rales heard over the lung bases and clubbing of the fingers. In a group of 21 insulation workers (Table 3) with definite asbestosis who were still at work, six were cyanosed, 7 showed clubbing of the fingers and 13 had basal rales. The signs became more frequent and marked as the disease progresses and

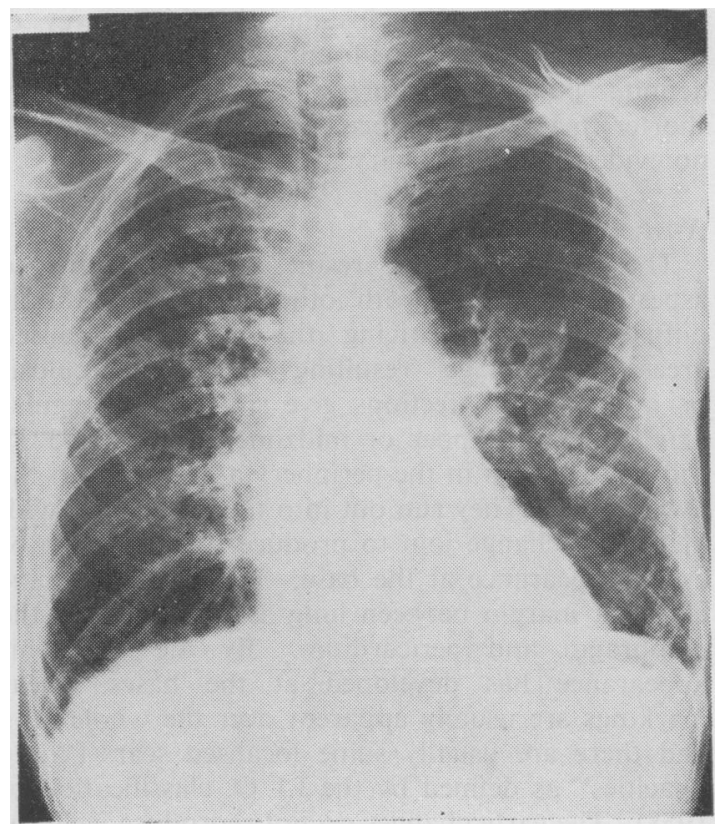

Fig. 4-Pipe coverer (insulation worker) for 26 years; died at the age of 71 years of cor pulmonale In addition to the diffuse fibrosis there is extensive calcification of pleural plaques more marked on the left than the right. There is some generalised pleural thickening and a loss of clear demarcation of both diaphragms and pericardium.

when definite signs of right heart failure appear the men are unable to work and are unlikely to survive the next acute respiratory illness. The rales and clubbing together present a pattern which it is easy to distinguish from chronic bronchitis. The rales have a characteristic fine "dry" character which is persistent in spite of deep breathing or coughing. They are often mistaken for a rub and are so described in the earlier literature. These signs are of no value in distinguishing asbestosis from other forms of chronic interstitial fibrosis with clubbing of the fingers. But with restriction of chest movement, kyphosis (loss of height) and cyanosis they are useful in the detection and assessment of asbestosis in workers on whom serial examinations

TABLE 3

Symptoms and Signs in Early Asbestosis in 21 Working Men With Definite Radiological Changes

Cough (other than 'in mornings only')

Spit ('During the day' as well as 'in mornings') Breathlessness (M.R.C. grade 2 or more)

Clubbing of the fingers ..

Warts

Cyanosis .

Basal 'dry' rales 
are carried out. For instance in this survey of insulation workers it was found that the 21 men with definite pulmonary fibrosis averaged $1 \frac{3}{4}$ inches shorter (making allowance for age) than those with no evidence of pulmonary fibrosis.

\section{$X$-ray changes}

The changes which result from exposure to asbestos can occur with other forms of chronic diffuse fibrosis involving the pleura. Localised areas of damage resulting from tuberculosis or intercurrent infections give rise to an irregular scarring in the upper or midzone (Figs. 2 and 3 ). Linear markings in the periphery appear first in the lower zones. They run out into the pleura and with increasing change join to produce a honeycomb or cystic appearance at the base. There is loss of the clear-cut margin between lung and pleura over the diaphragm and pericardium. By the time this appearance has developed at the bases, linear markings are usually apparent over the whole lung and there are usually some localised scars ("lung opacities" as defined by the I.L.O. classification of 1958). The early changes do not reproduce well but all the films (Figs. 2-6) show easily recognisable linear shadowing with loss of the clear-cut line of the pleura.

An adaption of the I.L.O. classification of X-ray changes in pneumoconiosis to make it applicable to asbestosis is at present under discussion (U.I.C.C. Report, 1965). This will enable the findings of different groups to be compared.

Pleural thickening, as opposed to the loss of clear demarcation between lung and pleura, can take two forms. The first is a diffuse thickening with ill-defined margins which is most marked over the lower lobes and is related in severity to the parenchymal change. The second is the formation of plaques which are circumscribed areas of hyaline fibrous tissue in the parietal pleura. On the dia- phragm or pericardium they are rounded, but on the chest wall they are guttate and lie along the line of the ribs usually from the mid-axillary line forward. They are not easy to sec on X-ray unti产 they begin to calcify. When calcified plaques have a characteristic appearance with clear cut margins and a bilateral distribution (as in Fig. 4) they are probably diagnostic of asbestos exposure. The $y_{\mathscr{D}}^{\mathbb{D}}$ may appear before the parenchymal changes and have been used by Kiviluoto (1965) to plot the environmental area of asbestos exposure in Finland: In the Belfast series of dead asbestos workers there were 13 with plaques out of the 87 for whom chest X-rays were available. In a survey of $100 \mathrm{~B}$ living pipe coverers of varying ages in the same area?. six showed plaques and the only one under 40 yearsit of age had been exposed in childhood.

Plaques are very common in and around thes anthophyllite mining areas in Finland and in? workers in Eastern Germany using anthophyllitew and other fibres. In South Africa they are seens both in the blue asbestos and in the amosite mining areas (Sluis-Cremer, 1965). The incidence in the chrysotile mining areas of Quebec varies from mineo to mine (Cartier, 1965). Although mesotheliomasp have developed in patients with calcified plaques they are not necessarily associated. Mesothelionga are unknown both in Finland, and in the amosiese areas of South Africa where plaques are quiteo common (Table 4).

\section{Laboratory tests}

No test, short of lung biopsy, is diagnostic of요 asbestosis, but some tests results support the $\overrightarrow{\vec{O}}$ diagnosis:-

Sputum: The sputum is mucoid unless there is? complicating bronchial infection. There are no? specific cytological changes but malignant cells mayo be found before there is other evidence of carcinoma. The sputum may contain both asbestos bodies and $\overline{3}$

TABLE 4

Geographical Relationship Between Plaques and Mesotheliomas

\begin{tabular}{|c|c|c|c|}
\hline Area & Fibre & Frequenc & $\begin{array}{l}\text { of } \\
\text { Mesotheliomas }\end{array}$ \\
\hline \multirow{4}{*}{ 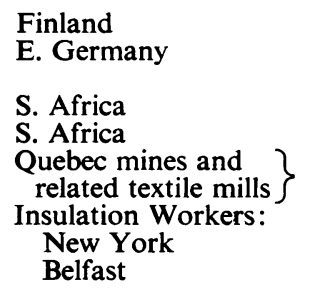 } & $\begin{array}{l}\text { Anthophyllite } \\
\text { Anthophyllite and } \\
\text { other fibres }\end{array}$ & \multirow{4}{*}{ 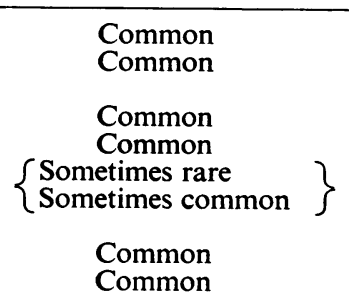 } & $\begin{array}{l}\text { None } \\
6 \text { since } 1957\end{array}$ \\
\hline & $\begin{array}{l}\text { Crocidolite } \\
\text { Amosite }\end{array}$ & & $\begin{array}{l}\text { Common } \\
\text { None }\end{array}$ \\
\hline & Chrysotile & & Rare \\
\hline & $\begin{array}{l}\text { Mixed } \\
\text { Mixed }\end{array}$ & & $\begin{array}{l}\text { Common } \\
\text { Common }\end{array}$ \\
\hline
\end{tabular}


fibres. These are not easy to see on direct examination. If the sputum is first treated with "Eusol" or antiformin and the sediment examined by phase contrast or with the substage condenser lowered asbestos bodies show up clearly (Gloyne, 1932). Polarised light may be needed to recognise the asbestos fibres. The presence of fibres only indicates current exposure and asbestos bodies indicate exposure in the recent or distant past. Neither can be considered proof either that the patient has asbestosis in the absence of definite $X$-ray changes or that the pulmonary fibrosis seen on X-ray is due to exposure to asbestos.

Respiratory function tests: When applied to groups of asbestos workers compared with comparable controls there are clear-cut differences. These result from:-

(i) Low total lung volume.

(ii) Low vital capacity without evidence of airways obstruction.

(iii) Low pulmonary compliance.

(iv) Low diffusing capacity (transfer factor).

Williams and Hugh-Jones (1960) reported abnormalities in diffusing capacity for carbon dioxide before X-ray changes in factory workers. But in Belfast insulation workers the carbon monoxide diffusion test is less sensitive than X-rays in detection of early evidence of asbestosis.

There is a large range of normal for all these tests and each may be made abnormal by a variety of diseases. Therefore the tests are of little value in the detection of early asbestosis in the individual case unless serial readings over previous years are available (Bader, Bader, Tierstein and Selikoff, 1965; Hunt, 1965). The extent of the diffusion defect is the best estimate of disability.

\section{The Complications of Asbestosis}

The pattern of morbidity and mortality amongst asbestos workers has changed as the conditions of work have improved. Just as children are no longer put into the sacks to stamp down the fibrous amosite in the mills in the South African mines (Schepers, 1965) so the machinery for cutting asbestos board in the modern factory is automated, enclosed and subjected to exhaust ventilation.

In some factories where crippling pulmonary fibrosis used to occur in less than 10 years, there are now men who have worked continuously since 1933 without any detectable evidence of pulmonary fibro is. Heavily exposed workers were unable to work in the factories for long enough for the late complications of asbestos exposure to appear while they were still at work. But those who left the work after a short period of exposure lived to develop carcinoma of the lung and mesothelioma of the pleura. These cases have only recently been brought to light by studies in which the fate of workers who left factories before 1933 are being traced (Newhouse, 1966).

The second factor which delayed the recognition of the malignant complications was the long interval between first exposure and the development of malignancy. The asbestos industry had started on a small scale at the end of the last century and continued to employ small numbers of men and women until the first World War. A large population did not reach the length of exposure or age for cancer until 1940 - 50.

Since 1931 all workers in the scheduled occupations in Great Britain have been registered and kept under medical supervision. Their deaths are reported to the coroner and a postmortem is usually carried out so from that time the cause of death amongst workers who were already in certain jobs in the asbestos industry is fairly accurately known. It was not until the figures for 1947 were published (H.M.S.O. 1949) that an undue incidence $(13 \%)$ of death due to cancer of the lung was noticed. Amongst the men there were no cases of cancer of the lung under the age of 45 but above that age they amounted to 22 out of 76 with a peak incidence in the 55 - 64 age group. Detailed studies on one asbestos textile factory has confirmed the high incidence of cancer of the lung (Knox, Doll and Hill, 1965) but indicate that only workers exposed to the heavy dust concentrations before 1933 were at risk. Although workers taken on after that date in that factory appear to run no greater risk of developing cancer of the lung than other sections of the population, the national figures still show a rising incidence. Nearly $50 \%$ of deaths in workers with certified asbestosis in the $1961-3$ period were due to intrathoracic tumours (Buchanan, 1965).

Studies from another asbestos factory (Smither, 1965) reveal a similar change in pattern (see Table 2). Tuberculosis has been replaced by primary carcinoma of the lung and by mesothelial tumours of the pleura and peritoneum. In Dresden the causes of death for asbestos workers have been recorded separately since 1952 (Jacob and Anspach, 1965). There were no cases of intrathoracic tumours among 18 deaths in the first year but in the next two five-year periods the incidence was $19 \%$ and $29 \%$ of 47 and 85 deaths respectively. One-fifth of these intrathoracic tumours were mesotheliomas of the pleura. The duration of exposure for these cases varied between two and 42 years (average 14.2 years) and the average latent period for all intrathoracic tumours was 30.7 years and for mesothelioma was 31.8 years.

The epidemiology and pathogenesis of these two tumours, cancer of the lung and mesothelioma, is 
still under investigation in relation to asbestos exposure.

\section{Cancer of the lung}

This appears to occur in workers exposed to any type of asbestos fibre but statistics are very fragmentary. It has been observed in all mining areas, but little accurate information is available to compare with the general population allowing for factors such as smoking and atmospheric pollution. Finland is a country with a high rate for cancer of the lung anyway and in all countries the rapidly rising incidence which has been attributed to cigarette smoking makes all such statistics difficult to interpret.

The factory populations (Knox, Doll and Hill, 1965; Smither, 1965; Jacob and Anspach, 1965) already mentioned show an incidence of pulmonary or pleural neoplasms of the order of $30 \%$ amongst men exposed to dusty conditions which are not sufficiently severe to cause death due to pulmonary fibrosis and respiratory failure in more than $20 \%$. This risk of cancer of the lung amongst workers exposed to factory conditions before any effort at dust suppression has been estimated as 15 times that expected.

The conditions under which insulators work have only changed gradually over the years. Part of this change has been due to the introduction of prefabricated materials which are easier and less dusty to handle. More recently materials which do not contain asbestos have been used. Although masks have been supplied for certain very dusty jobs such as limpet spraying no deliberate effort has been made to reduce the dustiness of this type of work.
In Belfast all insulators over 50 years of age and 3 30 years of exposure so far examined show definite $\stackrel{0}{\circ}$ evidence of pulmonary damage whereas only about. $30 \%$ of men between the ages of $30-40$ or with $\vec{F}$ 10-19 years of exposure show such evidence.? This suggests a degree of exposure less than that which existed in some of the factories before 1933, $\frac{\overline{\bar{c}}}{\overline{\mathrm{n}}}$ but more than that described by Knox and others? (1965) following that date. 107 deaths in insulators $อ$ in Belfast since 1940 have been investigated so far.ळ The causes of death are given in Table 5. There is $\vec{\circ}$ a moderately high incidence of non-malignantrespiratory deaths but it is not far in excess of that $\vec{\omega}$ expected as in the first half of the period tuberculosis was still relatively common. It has not been easyo to differentiate between deaths due to cancer of the lung and those due to pleural mesothelioma where $\hat{N}$ no autopsy material has been preserved. They have $\overrightarrow{0}$ been classified together and are about five times the? expected.

There has been no definite change in pattern of deaths amongst insulation workers over the years (see Fig. 6) apart from the disappearance of $\vec{O}$ pulmonary tuberculosis. The age of death, pro- $\frac{\infty}{+}$ portion of cases with pulmonary fibrosis and음 proportion with cancer have all remained the same $\stackrel{\mathbb{D}}{\stackrel{n}{ }}$ suggesting a constant level of exposure at least $\vec{\varphi}$ until 10 - 15 years ago.

Hammond, Selikoff and Churg (1965) have foumi an incidence of intrathoracic tumours in insulatioñ workers seven times the expected and also a high rate of gastrointestinal neoplasms. The peak mortality due to lung cancer for men in all reported $\frac{}{\varnothing}$ series of asbestos workers is between 55 and 60 을 years of age and the only clinical difference between $\overrightarrow{\vec{\partial}}$ these and other lung cancers is a higher proportion

\section{TABLE 5}

Cause of Death in Insulation Workers

BeLfast 1940 - 65

Total: 107 Mean Age: $55.3 \pm 11.25$ Years

\begin{tabular}{|c|c|c|}
\hline Cause & Observed & Expected $*$ \\
\hline $\begin{array}{l}\text { MALIGNANT :- } \\
\text { Intrathoracic neoplasms } \\
\text { Abdominal neoplasms } \\
\text { Other neoplasms }\end{array}$ & $\begin{array}{r}28 \\
15 \\
4\end{array}$ & $\begin{array}{l}5.3 \\
9.0 \\
6.7\end{array}$ \\
\hline $\begin{array}{l}\text { NoN-MALIGNANT :- } \\
\text { Pulmonary disease } \\
\text { Cardiac and circulatory } \\
\text { Other causes } \\
\text { Unknown }\end{array}$ & $\begin{array}{r}31 \\
21 \\
5 \\
3\end{array}$ & $\begin{array}{l}25.6 \\
37.1 \\
21.3 \\
-\end{array}$ \\
\hline
\end{tabular}




\section{Distribution of Deaths by Year of Death.}

$\begin{array}{ccccc}1940 & 1945 & 1950 & 1955 & 1960 \\ -44 . & -49 . & -54 . & -59 . & -64 .\end{array}$

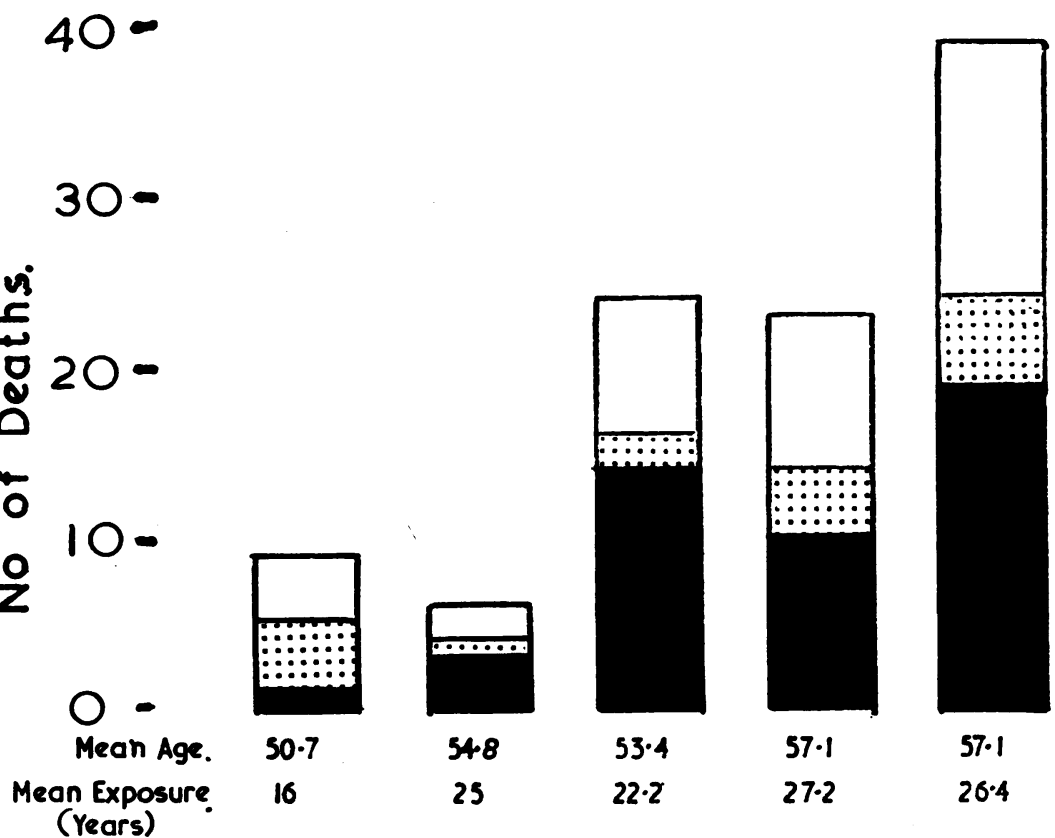

FIG. 5-The increasing number of deaths relating to successive five year periods may be due to increasingly efficient case finding rather than a change in the death rate among insulation workers.

TABLE 6

Mesotheliomas and Exposure to Asbestos

Examples of Retrospective Studies

\begin{tabular}{|c|c|c|c|c|c|c|}
\hline \multirow[b]{2}{*}{ Source } & \multirow{2}{*}{\multicolumn{2}{|c|}{ Total }} & \multicolumn{4}{|c|}{ Exposure } \\
\hline & & & Direct & Casual & $\begin{array}{c}\text { Environmental } \\
\text { or } \\
\text { Domestic }\end{array}$ & None \\
\hline $\begin{array}{l}\text { LoNDON } \\
\text { Newhouse \& Thompson } \\
\text { (1965) }\end{array}$ & $\begin{array}{l}\text { Cases } \\
\text { Controls }\end{array}$ & $\begin{array}{l}76 \\
76\end{array}$ & $\begin{array}{r}31 \\
8\end{array}$ & $\begin{array}{l}0 \\
0\end{array}$ & $\begin{array}{l}9 \\
1\end{array}$ & $\begin{array}{l}36 \\
67\end{array}$ \\
\hline $\begin{array}{l}\text { BELFAST } \\
\text { Elmes \& Wade (1965) } \\
\text { LIVERPOOL }\end{array}$ & $\begin{array}{l}\text { Cases } \\
\text { Controls } \\
\text { Cases }\end{array}$ & $\begin{array}{l}42 \\
42 \\
17\end{array}$ & $\begin{array}{l}8 \\
2 \\
7\end{array}$ & $\begin{array}{r}24 \\
7 \\
6\end{array}$ & $\begin{array}{l}\mathbf{0} \\
\mathbf{0} \\
\mathbf{0}\end{array}$ & $\begin{array}{r}10 \\
3 \\
4\end{array}$ \\
\hline $\begin{array}{r}\text { Owen (1965) } \\
\text { SouTH AFRICA }\end{array}$ & Controls & 0 & & & & \\
\hline $\begin{array}{l}\text { Wagner, Sleggs \& } \\
\text { Marchand (1960) }\end{array}$ & $\begin{array}{l}\text { Cases } \\
\text { Controls }\end{array}$ & $\begin{array}{r}33 \\
0\end{array}$ & 14 & 5 & 13 & 1 \\
\hline TOtaL $\ldots \quad \ldots$ & Cases & 168 & $\begin{array}{l}60 \\
36 \%\end{array}$ & $\begin{array}{l}35 \\
21 \%\end{array}$ & $\begin{array}{l}22 \\
13 \%\end{array}$ & $\begin{array}{l}51 \\
30 \%\end{array}$ \\
\hline
\end{tabular}




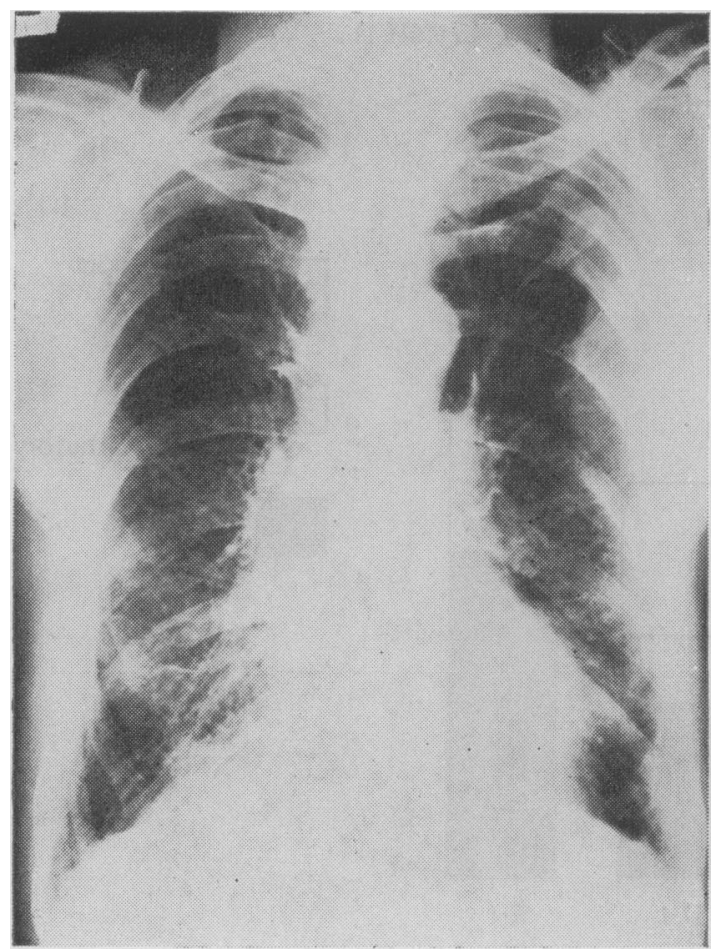

FIG. 6-Pipe coverer (insulation worker) for 26 years; died of a primary carcinoma of the lung aged 66 years. Linear marking and small opacities in the middle and lower zones. Loss of clear demarcation of the diaphragm and pericardium. The peripheral tumour in the left upper lobe is indistinguishable radiologically from a mesothelioma.

of lower lobe tumours (Jacob and Anspach, 1965).

The symptoms, signs and X-ray changes of cancer of the lung are too well known to require description here. Fig. 6 shows the chest film of an insulation worker with both asbestosis and a primary cancer of the lung. In all the cases of proven primary carcinoma of the lung in the Belfast series there was histological evidence of asbestosis, but this was not always obvious on X-ray.

\section{Mesothelioma}

Epidemiology: This tumour has been the subject of considerable research and comment since McCaughey (1958) described a series of cases in Belfast and Wagner and others (1960) related an even larger series to environmental exposure to blue asbestos. The histological evidence relating mesothelioma to the inhalation or ingestion of asbestos is very impressive. When a history of exposure to asbestos is looked for in cases of mesothelioma it can usually be found (Table 6). But in only a third of cases is this exposure of the sort of intensity that might

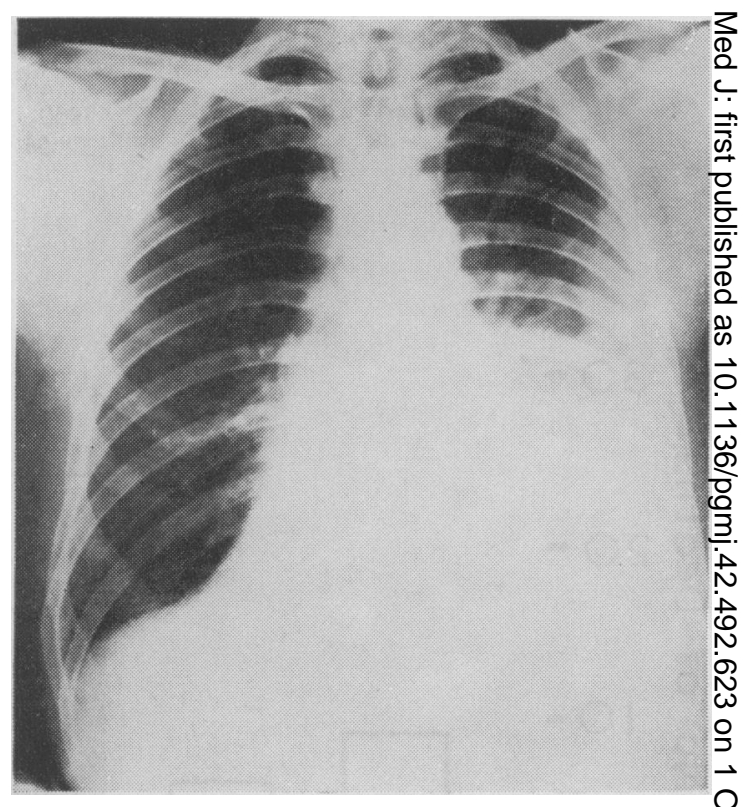

FIG. 7-Pipe coverer (insulation worker) for nearly $30 \frac{\rho}{0}$ years; died at 44 years of a mesothelioma of theo left pleura. The tumour is visible above the level of the left basal effusion. There is a partial collapse of the right lower lobe. Pulmonawy fibrosis, though present, is not sufficient to show? in the reproduction.

cause asbestosis or carcinoma of the lung. In another third of the cases there is an apparently trivial exposure at work or in the home environment. 0 The environmental exposure ranged from playing $\overrightarrow{0}$ on the slag heaps outside an asbestos mine up to 3 the age of seven years in a woman who died of a mesothelioma at the age of 35 (Wagner, Sleggs and Marchand, 1960) to the woman who developed ao mesothelioma at 63 years and who used to wash? out her daughter's overalls when the latter worked in an asbestos factory (Newhouse and Thompson, 1965). Casual exposure at work ranged fromo occasionally having to remove the remains of lagging from machinery which was being dismantled윽 for servicing, to the repairing of hessian bags some $>$ of which had been used for asbestos (Owen, 1965).

The relatively large group (30\%) with no history of exposure can be accounted for in three ways:-

1. Occupational exposure which the patient had forgotten or in which he was unaware of the nature of the materials handled.

2. Environmental or domestic exposure of which the patient was unaware.

3. No exposure at all.

In (1) and (2) one would expect to find asbestos $\frac{T}{\circ}$ bodies or fibres in the lungs. In a retrospective $\stackrel{\vec{D}}{\vec{P}}$ study of 20 patients dying with asbestos bodies in $\frac{?}{\mathbb{Q}}$ 
the lungs the source of exposure was only found in 14 (Elmes and Wade, 1965). This deficit could account for all the mesotheliomas for whom no history of exposure is obtained. Nevertheless there remains the possibility from epidemiological studies that a small proportion of mesotheliomas occur in patients who have never been exposed to asbestos.

Because of the trivial exposures recorded in a third of the cases and the increasing and manifold use to which asbestos has been put we can expect an increasing number of mesotheliomas at least over the next $\mathbf{4 0}$ years. (In the London series the interval between first exposure and death varied between 29 years for factory exposure and 48 years for environmental exposure. For the Belfast group as a whole the interval was 43 years \pm 13 ).

Numerous cases of mesothelioma have been identified amongst people who have lived or worked in blue asbestos mining areas in South Africa (Table 4) and cases have been reported from the area around the crocidolite mines in Western Australia. No cases have been reported from around the amosite mines in South Africa or the anthophyllite mines in Finland and only two cases from the Quebec chrysotile mining area. Much factory work entails exposure to mixed dusts but so far the evidence from the factories indicates that frequency of mesotheliomas may vary with the extent to which blue asbestos is used. In insulation workers it is usually impossible to identify the extent to which individual workers have been exposed to individual types of asbestos. The incidence of mesothelioma amongst these workers and amongst other workers exposed to the same materials is relatively high.

Clinical features of mesothelioma: This tumour occurs in either sex and people exposed during childhood may develop it earlier than those exposed during adult life. The age of onset varies from 31 years to 83 years and the mode for most series lies between 55 and 65 years. Other evidence of asbestos exposure (clubbing of the fingers, asbestos warts, pulmonary fibrosis and basal rales) is often absent.

\section{Pleural cases}

Mode of onset: This usually starts with gradually increasing pain or breathlessness, taking several weeks before the patient seeks medical advice. Because of this insidious onset the condition may be found accidentally. One patient recently was admitted to hospital with a fall, another with severe influenza and yet another was submitted to routine chest $\mathrm{X}$-rays as part of an occupational survey. Only on direct questioning was the history of pain or breathlessness elicited. The onset of both symptoms is sometimes so gradual that the patient is unable to say which symptom started first. The pain is described as a heavy feeling and confined to the affected side of the chest at first and then radiates to the shoulder and epigastrium.

It becomes more severe, a "dull toothache" little influenced by respiration on movement unless there is a secondary frozen shoulder.

In a few cases breathlessness comes on in a matter of hours or 2-3 days, and in these cases there is usually a large pleural effusion which is sometimes bloody. But even in these cases there is seldom much evidence on examination of a shift of the mediastinum to the opposite side. As the tumour extends around the lung there is restriction of movement on that side with a shrinking down of the whole of that side of the chest and a pulling over the heart and mediastinum to the affected side. Tumour may become palpable in the supraclavicular fossa and between the ribs but seldom grows through the chest wall unless it is along the track of a thoracentesis needle, through a thoracotomy wound, at the site of a fractured rib or through an area of chest wall damaged by deep X-ray therapy.

$\mathrm{X}$-ray appearances (see Fig. 7) are indistinguishable in most cases from a simple pleural effusion with or without some degree of pulmonary fibrosis. The actual tumour may not be visible until the fluid is aspirated when it usually shows up as a lumpy area in the pleura which also shows some degree of thickening all round the lung. Rib destruction appears late and local lymph node enlargement is rarely apparent on X-ray.

Diagnosis: This can often be made on clinical grounds after the exclusion of other causes of persistent pleural effusion in the middle-aged or elderly and the failure to find a distant primary malignancy. It is difficult to verify the diagnosis. The fluid, when clear, is often unusually viscous, but frequently contains fresh or altered blood. Cytological examination of the fluid may reveal cells strongly suggestive of mesothelioma but the diagnosis should not be based on this alone (Klempman, 1962; Naylor, 1963). The presence of hyaluronic acid (Harrington, Wagner and Smith, 1963) is also strongly suggestive but may occur with other malignant lesions of the pleura. The presence of blood interferes with this test.

Especially in the absence of free fluid the diagnosis can only be verified by biopsy, but there is a variation in the histological appearance in different parts of a single tumour. There are often extensive areas of fibrous tissue which are indistinguishable from chronic inflammatory disease. Therefore needle biopsy, and even limited surgical biopsy, may fail to provide the pathologist with sufficient material to make the correct diagnosis. An open thoracotomy must be performed and pieces of tissue from different areas taken. To avoid tumour growing through the thoracotomy wound Thompson 
(1965) advocates the instillation of nitrogen mustard into the pleural cavity at the end of procedure.

Treatment: Neither radical surgery nor radiotherapy can improve the prognosis and both may encourage direct extension of the tumour through the chest wall. Palliative treatment should be restricted to removal of the pleural fluid to relieve breathlessness and instillation of nitrogen mustard into the space if the accummulation of fluid is rapid. Pain due to infiltration of the chest wall and vertebrae does not usually respond to radiation or systemic cytotoxic drugs; it is usually too extensive for treatment by regional nerve root section.

Course and prognosis: Patients seldom survive more than a year from the time the diagnosis is established. The survival from onset of symptoms or from the earliest X-ray changes may be considerably longer but four years is probably the maximum. Apart from increasing pain and breathlessness the patients usually remain in good health until invasion of the mediastinal tissue interferes with nutrition and they lose weight. Death is usually due to restriction of ventilation but intercurrent chest infection may complicate the terminal illness.

\section{Peritoneal cases}

The onset is even more insidious than in the pleural cases. The symptoms may mimic any form of abdominal neoplasm, presenting as upper or lower gastrointestinal tract obstruction with or without pain. Sometimes painless ascites is the presenting feature. The diagnosis can usually only be established by laparotomy and adequate biopsy but occasionally cytology of the fluid may be sufficient. Weight loss occurs earlier than in the pleural lesion but the interval between diagnosis and death is the same. No treatment is of any value except that the rapid re-accumulation of ascitic fluid can be checked by local nitrogen mustard therapy.

\section{Summary and Conclusions}

Pulmonary fibrosis due to exposure to asbestos dust in factory workers has become uncommon and when it occurs is less severe than it was before the introduction of dust suppression measures in $1932-33$. However there remain occupations which were not covered by the Merewether report which can cause sufficiently severe fibrosis to lead to death before the retiring age. Insulation workers are a group in which this is likely to occur but the spreading use of asbestos in the building industry may be leading to similar levels of exposure among occupational groups where this hazard has not existed before.

An increase in the number of such cases can only be prevented by constant vigilance on the part of the medical profession in identifying this as a cause of diffuse pulmonary fibrosis in individual cases and 0 bringing them to the notice of the factory inspector $-c$ ate. One of the difficulties here is the lack of clinical $\overrightarrow{\vec{\rho}}$ features to distinguish asbestosis from other formso of diffuse fibrosis. When the source of exposure iso not obvious open biopsy of the lung may be necessary to establish the cause and initiate investigation for sources of exposure.

Carcinoma of the lung resulting from exposureto asbestos appears to be common in patients whoseexposure to the dust was insufficiently long or $\vec{\omega}$ intense to cause crippling fibrosis. There is evidence that the risk may have been eliminated by theo application of thorough dust suppression under. factory conditions. But there may be many other $\mathrm{N}$ workers handling asbestos who are still at risk as has been shown for insulation workers. The nature, N age of onset and course of cancer of the lungN secondary to asbestos exposure does not appear to differ greatly from cases arising in the general ${ }^{3}$ population.

A rapidly increasing number of cases of mesothe $-\frac{\AA}{0}$ lioma of the pleura and peritoneum have been recognised in the last 10 years. It is an invariabdy fatal tumour for which there is no satisfactofy palliative treatment. There is an association. between exposure to asbestos and the development of this tumour. The degree of exposure in many? cases is slight and indicates that many people may by now have had sufficient exposure either in the course of their work, hobbies or in the home. As $\frac{\mathbb{\Phi}}{\varnothing}$ there is no evidence of another factor operating in $\Rightarrow$ the initiation of this tumour it seems likely that 3 increasing numbers of cases will arise in the next $\vec{F}$ 30 years. Prevention of further cases beyond that date depends on the restriction of use and greater precautions in the handling of all types of asbestos 3 . fibre now. It is possible that the elimination of 0 one type of fibre (crocidolite) from commercial use 3 . might reduce the incidence of the tumour very considerably.

In writing this article I have drawn on information which has become available as a result of research work $N$ done in the Department of Therapeutics and Pharma- $N$ cology by Professor O. L. Wade, Dr. Jean H. M. Langlands and Dr. W. F. M. Wallace as well as myself some of which has not yet been published. This work $\sigma$ is part of a collaborative study of the problem of asbestos exposure organised by Dr. J. C. Gilson, Director of the M.R.C. Pneumoconiosis Research Unit at Cardiff. The $\bar{\varnothing}$ Biological Effects of Asbestos were discussed at an $\stackrel{\oplus}{+}$ International Symposium held in New York under the $\square$ auspices of the New York Academy of Sciences in $\overline{0}$ October 1964. For convenience I have quoted references $\frac{\vec{D}}{\mathrm{D}}$ to the proceedings of this Symposium although much of $\stackrel{\rho}{\square}$ the work has also been published elsewhere. 


\section{REFERENCES}

Bader, M. E., Bader, R. A., Tierstein, A. S., and

Selikoff, I. J. (1965): Pulmonary Function in Asbestosis. Several Tests in a Long Term Prospective Study, Ann. N.Y. Acad. Sci., 132, 391.

Buchanan, W. D. (1965): Asbestosis and Primary Intrathoracic Neoplasms, Ann. N.Y. Acad. Sci., 132, 507.

Carey, G. C. R., Elwood, P. C., McCaulay, I. R., Merrett, J. D., and Pemberton, J. (1965): Byssinosis in Flax Workers in Northern Ireland. Belfast: H.M.S.O.

CARTIER, P. (1955): Some Clinical Observations of Asbestosis in Mine and Mill Workers, A.M.A. Arch. Indust. Health, 11, 204.

Cartier, P. (1965): Discussion on Pleural Plaques, Ann. N.Y. Acad. Sci., 132, 387.

Cooke, W. E. (1927): Pulmonary Asbestosis, Brit. med. J., ii, 1024.

Elmes, P. C., and WAde, O. L. (1965): Relationship between Exposure to Asbestos and Pleural Malignancy in Belfast, Ann. N.Y. Acad. Sci., 132, 549.

Gloyne, S. R. (1932): The Asbestosis Body, Lancet, i, 1351.

Hammond, E. C., Selikoff, I. J., and Churg, J. (1965): Neoplasia among Insulation Workers in the United States with Special Reference to Intraabdominal Neoplasia, Ann. N.Y. Acad. Sci., 132, 519.

HARRINGTON, J. S. (1962): Natural Occurrence of Oils Containing 3-4-benzpyrene and Related Substances in Asbestos, Nature (Lond.), 193, 43.

Harrington, J. S., Wagner, J. C., and Smith, M. (1963): The Detection of Hyaluronic Acid in Pleural Fluids of Cases with Diffuse Pleural Mesotheliomas, Brit. J. exp. Path., 44, 81 .

Hunt, R. (1965): Routine Lung Function Studies on 830 Employees in an Asbestos Processing Plant, Ann. N. Y. Acad. Sci., 132, 406.

H.M.S.O. (1949): Annual Report of the Chief Inspector of Factories for the Year 1947, p. 79. London: H.M.S.O.

H.M.S.O. (1953): Thirtieth Annual Report of the Registrar General for the Year 1951. Belfast: H.M.S.O.

JACOB, G., and ANSPACH, M. (1965): Pulmonary Neoplasia among Dresden Asbestos Workers, Ann. N.Y. Acad. Sci., 132, 536.

Kiviluoto, R. (1965): Pleural Plaques and Asbestos: Further Observation on Endemic and other Nonoccupational Asbestosis, Ann. N.Y. Acad. Sci., 132, 235.
KlempMan, S. (1962): The Exfoliative Cytology of Diffuse Pleural Mesothelioma, Cancer, 15, 691.

KnoX, J. F., Doll, R. S., and Hill, I. D. (1965): Cohort Analysis of Changes in Incidence of Bronchial Carcinoma in a Textile Factory, Ann. N.Y. Acad. Sci. $132,526$.

McCAughey, W. T. E. (1958): Primary Tumours of the Pleura, J. Path. Bact., 76, 517.

Merewether, E. R. A., Price, C. W. (1930): Effects of Asbestos Dust on Lungs and Dust Suppression. London: H.M.S.O.

NAYLOR, B. (1963): The Exfoliative Cytology of Diffuse Malignant Mesothelioma, J. Path. Bact., 86, 293.

Newhouse, M. L., and Thompson, H. (1965): Mesothelioma of the Pleura and Peritoneum following Exposure to Asbestos in the London Area, Brit.J. industr. Med., 22, 261.

Newhouse, M. L. (1966): Personal Communication.

Oliver, SiR T. (1927): Clinical Aspects of Pulmonary Asbestosis, Brit. med. J., ii, 1026.

OWEN, W. G. (1965): Mesothelial Tumours and Exposure to Asbestos Dust, Ann. N.Y. Acad. Sci., 132, 674.

SeILER, H. E. (1928): A Case of Pneumoconiosis: the Result of Inhalation of Asbestos Dust, Brit. med. J., ii, 982.

SchePERS, A. W. H. (1965): Discussion on 'Human Exposure to Asbestos: Community Studies,' Ann. N.Y. Acad. Sci., 132, 246.

Sluis-Cremer, G. K. (1965): Asbestosis in South Africa - Certain Geographical and Environmental Considerations, Ann. N.Y. Acad. Sci., 132, 215.

Smither, W. J. (1965): Secular Changes in Asbestosis in an Asbestos Factory, Ann. N.Y. Acad. Sci., 132, 166

Thompson, V. C. (1965): Clinical Aspects of DiffuseMesothelial Tumours, Proc. Thor. Soc., Thorax, 20, 286.

U.I.C.C. INTERNATIONAL UNION AGAINST CANCER (1965): Report and Recommendations of the Working Group on Asbestos and Cancer, Ann. N.Y. Acad. Sci., 132, 706.

Wagner, J. C., Sleggs, C. A., and Marchand, P. (1960): Diffuse Mesothelioma and Asbestos Exposure in the North West Cape Province, Brit. J. industr. Med., 17, 260.

Williams, R., and Hugh-Jones, P. (1960): Lung Function Changes in Asbestosis, Thorax, 15, 109.

Wood, W. B. (1928): Pulmonary Asbestosis, Tubercle (Edinb)., 10, 353.

WYers, H. (1949): Asbestosis, Postgrad. med. J., 25, 631. 